\title{
CONTROLE DE PLANICIDADE NO LAMINADOR DE TIRAS A QUENTE 2 DA USIMINAS CUBATÃO*
}

\author{
Bruno Serafim Parra ${ }^{1}$ \\ Pedro Segundo da Silva Vallin² \\ Marcos Roberto Soares da Silva ${ }^{3}$
}

\section{Resumo}

O novo laminador de tiras a quente da Usiminas, instalado na usina de Cubatão em 2012, tem como diferencial o alto nível de automatismo para fornecer bobinas com melhor qualidade. Dentre os modelos matemáticos de controle existentes no laminador, apresenta-se o Automatic Profile Flatness Control (APFC), responsável pela medição de planicidade e controle de perfil das bobinas. Através da resposta do medidor de planicidade e do medidor de perfil na saída do trem acabador, o modelo utiliza informações gerais do laminador para gerar uma resposta dinâmica e eficiente da forma do material durante seu processamento. O modelo utiliza ferramentas dedicadas para o controle de forma, como o sistema de pair cross, que é o cruzamento voluntário dos cilindros entre tiras, o sistema de roll shift, responsável pela movimentação longitudinal dos cilindros entre tiras e o roll bender, este dinâmico, trabalhando na deformação dos cilindros. Desde o início da laminação comercial, o desempenho da planicidade do material apresentou evolução significativa na nos índices de qualidade e produtividade do laminador.

Palavras-chave: Planicidade; Automatic profile flatness control; Laminação a quente.

\section{FLATNESS CONTROL OF USIMINAS CUBATÃO HOT STRIP MILL 2 Abstract}

The new hot strip mill of Usiminas Cubatão plant has the characteristic of the high level of automation to provide coils with high quality and restricted dimensional tolerances. One of all mathematical models presented to control the hot strip mill process, the Automatic Flatness Control Profile (APFC) is responsible for flatness measurement and thickness profile control of the coils thru the response of flatness meter and width measure of the delivery side of finishing mill. The model uses general information of the mill to provide a dynamic and efficient response of the shape of the material during the hot processing. The model use dedicated tools to control the flatness like the pair cross system, which is a voluntary crossing of the strips between rolls, the roll shift system responsible for the longitudinal movement of the cylinder between the strip and the dynamic roll bender, to control the bending forces of the working rolls. Since the beginning of commercial rolling, flatness of the material's performance showed significant improvement in the quality and productivity of the rolling mill.

Keywords: Automatic profile flatness control; Mathematical model; Hot strip mill.

1 Engenheiro de Materiais, Mestre em Engenharia de Materiais, Engenheiro de Produção, Laminação a Quente, Usiminas, Cubatão, São Paulo, Brasil.

2 Engenheiro Mecânico, Especialista de Produção, Laminação a Quente, Usiminas, Cubatão, São Paulo, Brasil.

3 Engenheiro Metalurgista, Gerente Suporte Técnico, Laminação a Quente, Usiminas, Cubatão, São Paulo, Brasil. 


\section{INTRODUÇÃO}

A exigência por controles de forma evoluiu rapidamente em produtos laminados a quente e a frio, majoritariamente em produtos automotivos, linha branca e mercado de petróleo e gás. Em busca de soluções para defeitos de ondulações laterais, centrais e intermediárias, estudos levaram a melhorias nos materiais através de simulações matemáticas e novos equipamentos automatizados de controle e melhoria da planicidade [1,2]. Focado em atender as novas expectativas do mercado, a USIMINAS instalou em Cubatão o laminador de tiras a quente 2 (LTQ 2), com o enobrecimento de seus produtos nos quesitos de homogeneidade de propriedades mecânicas, estabilidade dimensional e melhoria de forma [3]. O novo laminador de tiras a quente conta com um forno de reaquecimento, um laminador reversível, seis cadeiras de laminação e duas bobinadeiras, conforme layout esquemático abaixo - Figura 1.

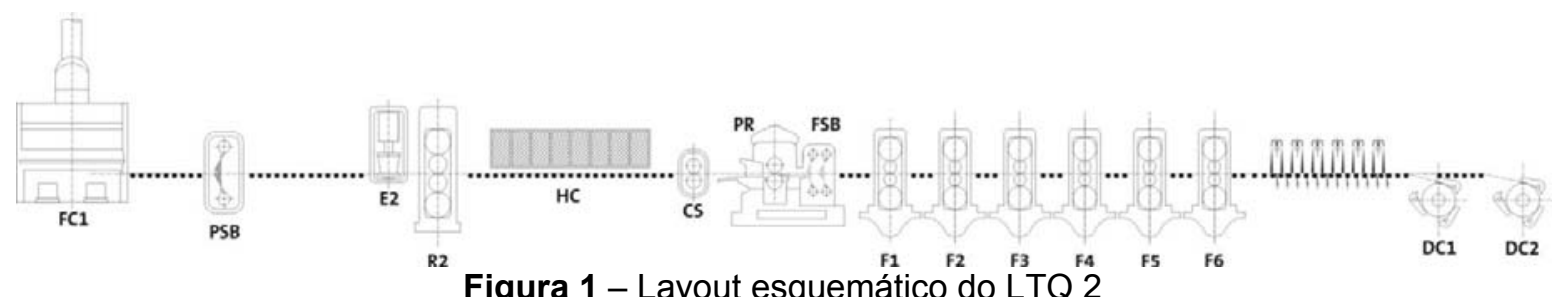

Figura 1 - Layout esquemático do L L TQ 2

Neste trabalho serão apresentados os principais parâmetros de controle e funcionalidades do modelo de planicidade de tiras a quente - Automatic Profile \& Flatness Control (APFC) do novo laminador de tiras a quente da USIMINAS, bem como resultados preliminares durante produção comercial, atendendo mercado interno e externo de diferentes setores industriais.

\section{MATERIAIS E MÉTODOS}

O APFC trabalha visando a melhoria da forma do material de maneira dinâmica, para a tira que está sendo laminada, e também para volumes de mesmo lote a serem processados, através de armazenamento e aprendizado com os resultados. Para tal, utiliza informações de setup e feedback do laminador, além das informações dos medidores de perfil (Multi Function Gagemeter - MFG) e de planicidade (Flatness Gagemeter - FLT).
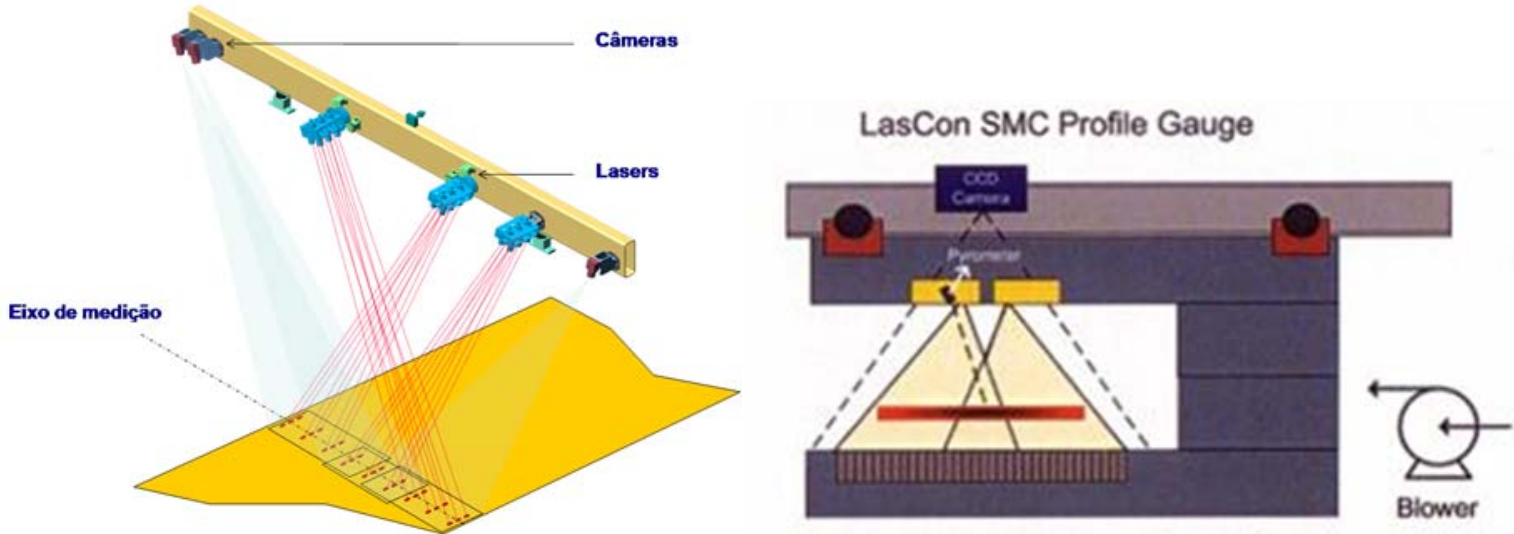

Figura 2 - Modo de leitura do medidor a laser de planicidade FLT (a) e Raio-X de perfil MFG (b) 
O medidor de planicidade FLT - Figura $2 a$ - trabalha com três emissores de lasers, gerando até nove faixas (de acordo com a largura) de medição ao longo da largura do material - esquematizado na Figura 3, e capta o resultado obtido através de câmeras que comparam as medições com um caixote virtual de calibração, disponibilizando as informações através de gráficos em linha - Figura 4a - e gráfico 3D - Figura 4b.

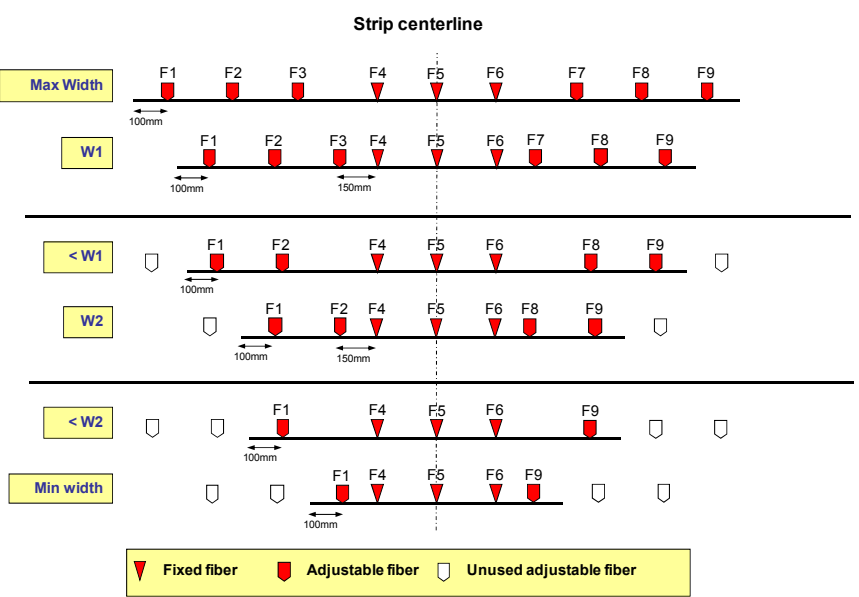

Figura 3 - Posicionamento das fibras fixas e móveis de medição
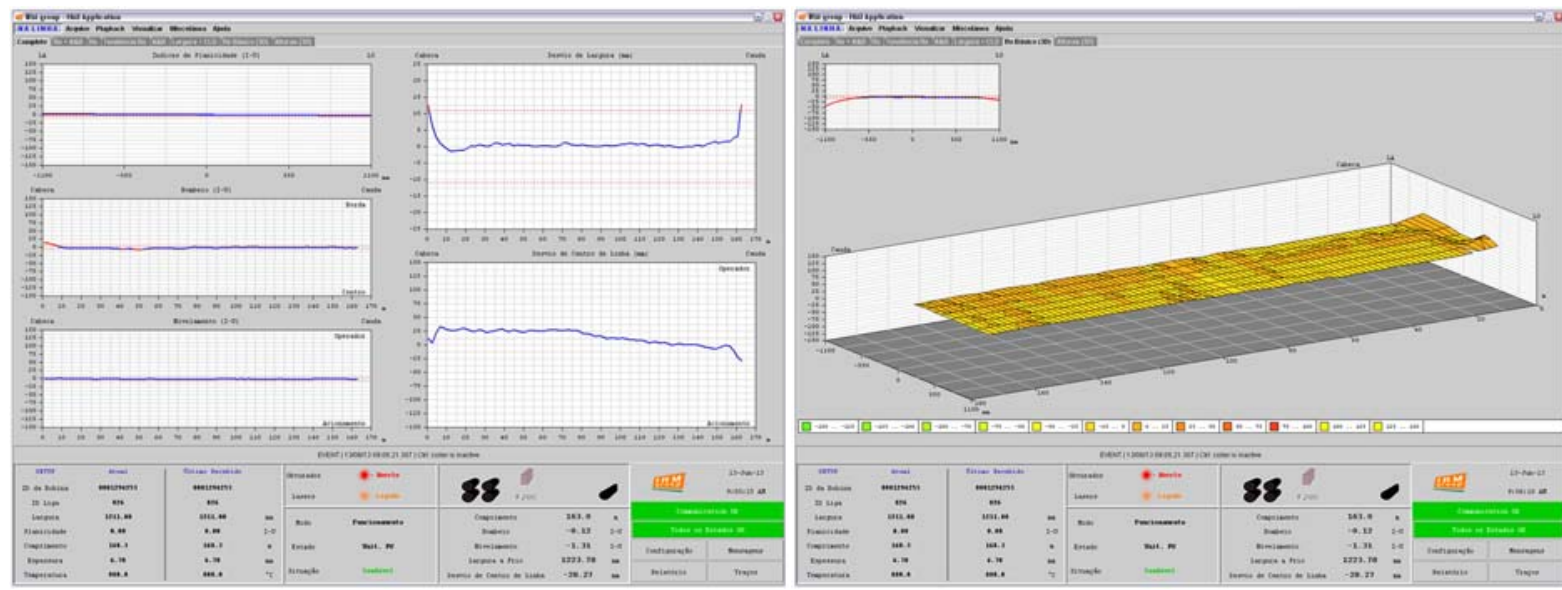

Figura 4 - Disposição dos resultados do equipamento FLT em linha (a) e gráfico 3D (b)

O medidor MFG por sua vez atua na medição das variáveis de espessura, largura, coroa e cunha em diferentes distâncias da borda (25 / 40 / 75 e 100 mm), perfil de espessura e temperatura da tira ao longo do comprimento. Para o controle de planicidade, as medições do MFG que são utilizadas são as de coroa, cunha e perfil. Nas figuras 5 e 6 são apresentados exemplos de gráficos gerados pelo MFG para perfil médio e perfil ao longo do comprimento, respectivamente.

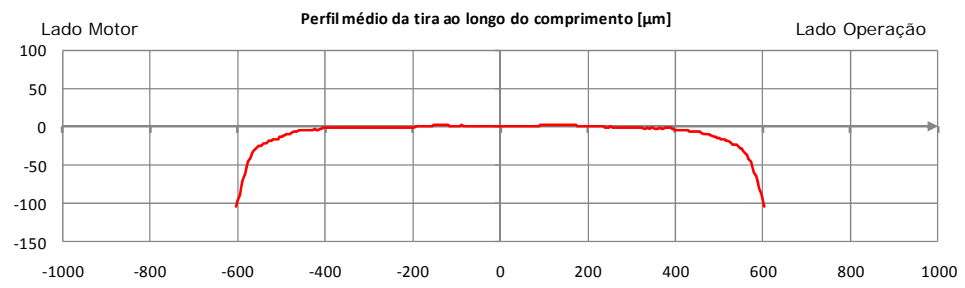

Figura 5 - Disposição do perfil médio pelo equipamento MFG 
Lado Operação

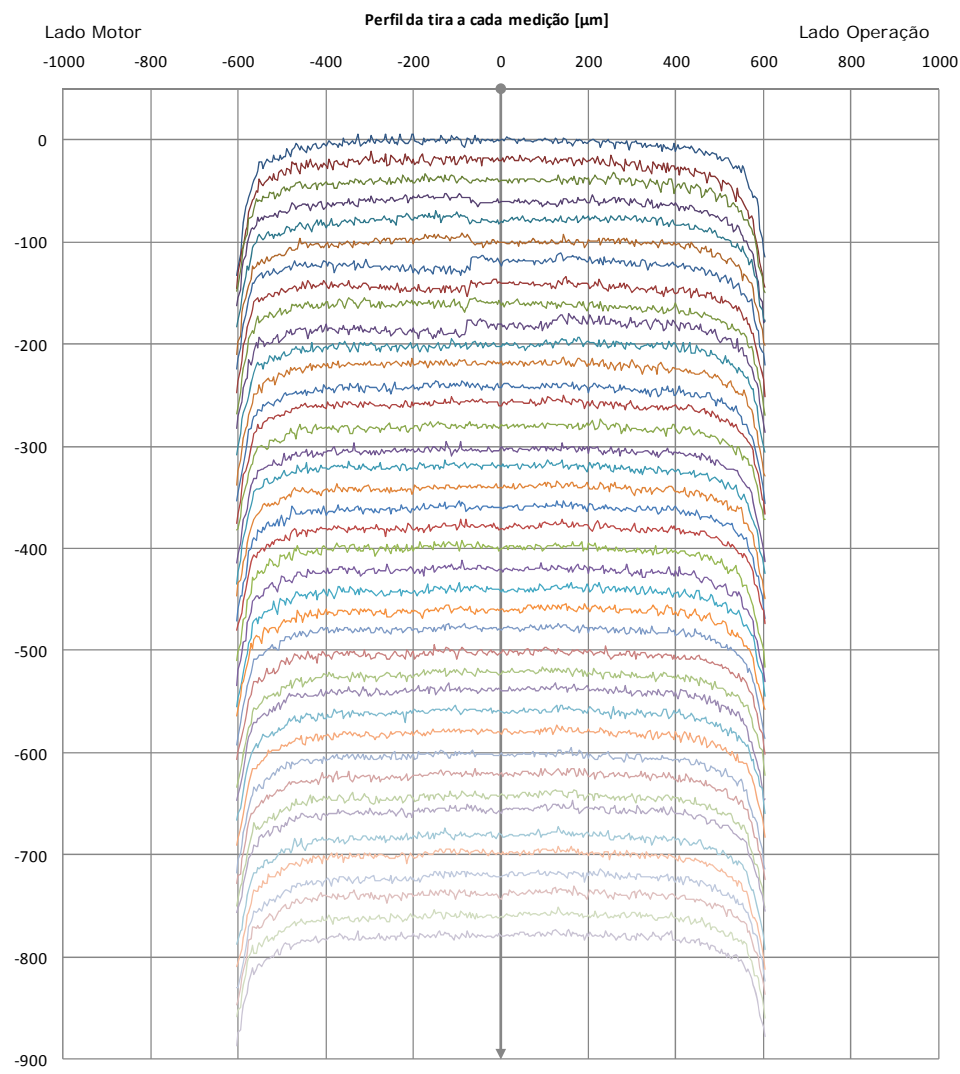

Figura 6 - Disposição dos perfis da tira pelo equipamento MFG

As funcionalidades do APFC para a correção e manutenção da planicidade do material laminado se resumem em três ferramentas de atuação no laminador de tiras a quente:

- Pair Cross - Cruzamento voluntário dos cilindros de trabalho e de encosto entre tiras, em função do valor de coroa objetivado. Presente nas cadeiras F1 a F4 do trem acabador.

- Work Roll Bender - Flexão dos cilindros de trabalho, com atuação dinâmica e atuação conjunta de setup, operador e correção instantânea pelo APFC após medição da planicidade na saída do trem acabador. Presente nas cadeiras F1 a F6 do trem acabador, sendo nas duas últimas cadeiras com o recurso de bender positivo e negativo.

- Work Roll Shift - Movimentação longitudinal dos cilindros de trabalho entre tiras, com a função de reduzir e amenizar o desgaste dos cilindros, possibilitando campanhas de laminação mais extensas e flexíveis.

Os requisitos para a atuação do APFC na correção e controle do perfil e planicidade da tira laminada são:

- Perfil objetivado na saída do trem acabador

- Limitação de planicidade de cada cadeira

- Condições de laminação (força de laminação, perfil de cilindros)

O propósito do modelo, que trabalha em todos os volumes produzidos:

- Alta qualidade de perfil da tira \& planicidade durante toda a extensão da bobina

- Laminação estável 
Os parâmetros de controle, por sua vez, para que se atinjam os resultados esperados, são:

- Cálculo de deformação de cilindros e da tira

a. Modelo de deformação de cilindros

b. Modelo de deformação da tira

c. Coeficientes efetivos de coroa / forma da tira

- Cálculo de perfil dos cilindros

a. Cálculo de coroa térmica dos cilindros

b. Cálculo do desgaste de cilindros

c. Cálculo da forma de cilindros

i. Cálculo de setup do WR Shift

- Cálculo do perfil da tira / planicidade (Setup de PC / Bender)

- Adaptação do modelo

- Controle dinâmico (correção do Bender durante a laminação)

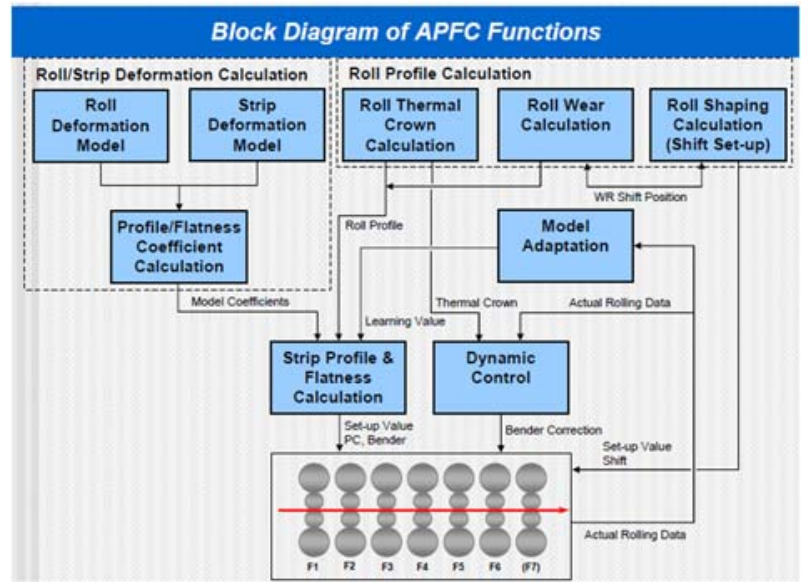

Figura 7 - Diagrama de bloco das funções do APFC

\section{RESULTADOS E DISCUSSÃO}

Os materiais foram divididos por família e classe dimensional para uma análise dos resultados de planicidade obtidos, abrangendo todo o mix de laminação, conforme Tabela 1. Para cada bobina, a região analisada foi a dos 150 metros iniciais distância da F6 até a bobinadeira, desconsiderando 25 metros iniciais, região de estabilização do material.

Tabela 1. Classes consideradas para análise dos resultados

\begin{tabular}{ccc}
\hline Famílias & $\begin{array}{c}\text { Faixas de } \\
\text { Espessura (mm) }\end{array}$ & $\begin{array}{c}\text { Faixas de } \\
\text { Largura }(\mathbf{m m})\end{array}$ \\
\hline Comum sem Liga - CSL & 1,50 a 2,50 & 750 a 1150 \\
\hline Ultra Baixo Carbono - ULC & 2,51 a 4,00 & 1151 a 1350 \\
\hline Grão não Orientado - GNO & 4,01 a 8,00 & 1350 a 1600 \\
\hline Resistente a Corrosão - RCO & 8,01 a 14,50 & 1601 a 2050 \\
\hline Microligado - MIL & 14,51 a 20,50 & \\
\hline Dual Phase - DPH & \\
\hline API & \\
\hline
\end{tabular}

A família CSL concentra maior parcela do Mix de laminação do LTQ2, sendo a dimensão de maior número de laminações na faixa de 2,51 a 4,00 mm por 1151 a $1350 \mathrm{~mm}$. Os resultados obtidos são considerados excelentes em valor absoluto e 
também em desvio padrão, visto que o material não exige grandes esforços do laminador e adquiriu aprendizado ao longo dos processamentos. Todos os resultados médios estão abaixo dos 15 I-Units, podendo ser considerados isentos de defeitos de planicidade.

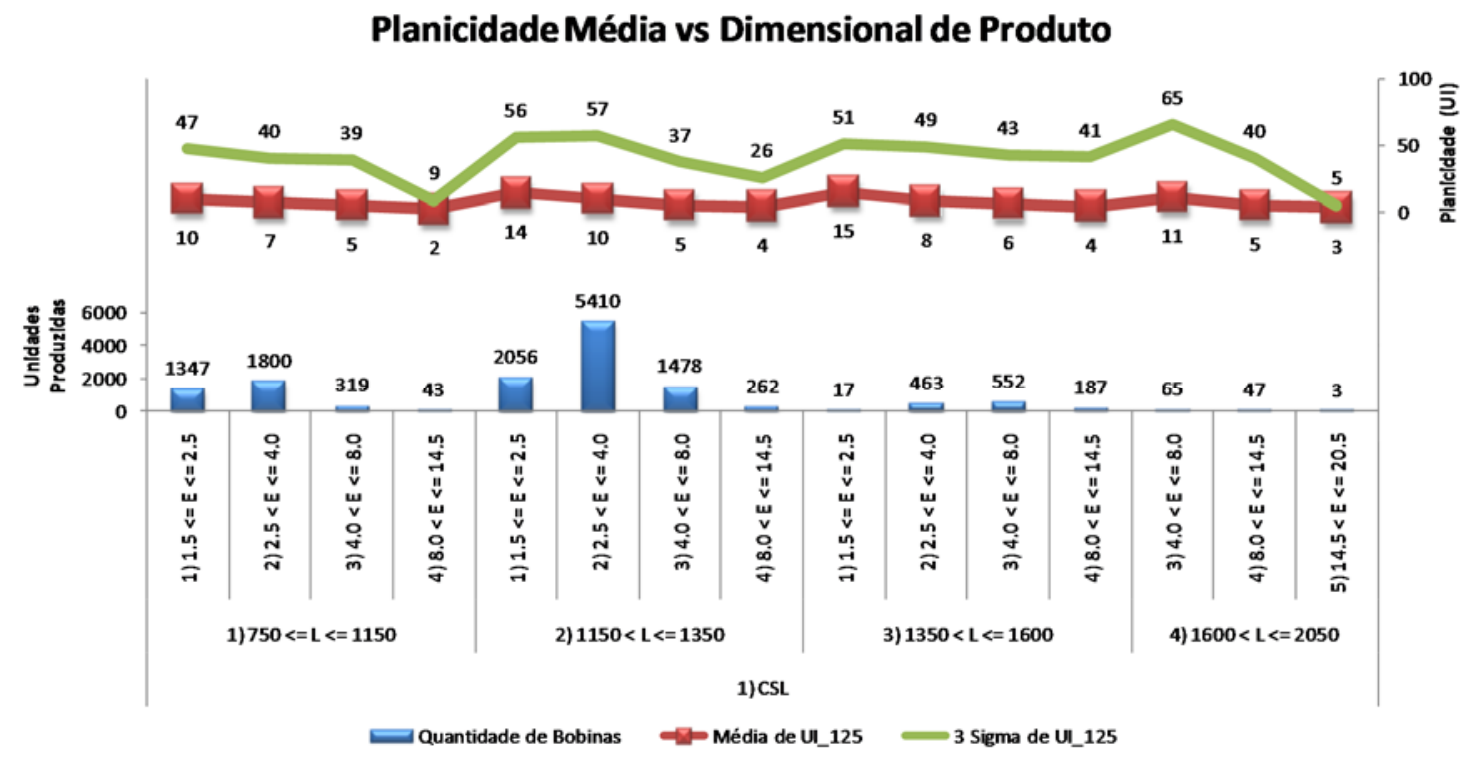

Figura 8. Resultado de planicidade da família CSL.

Na Figura 9 estão contidos os resultados das famílias ULC, GNO e RCO, as três com menor número de unidades produzidas e destaque para o ótimo resultado de planicidade. Para o material ULC, os valores médios também se mantêm abaixo dos 15 I-Units com baixo desvio padrão, devido estabilidade deste material no laminador. No caso do GNO, há um volume considerável de volumes finos, com espessura menor ou igual a 2,50 mm, e resultado abaixo dos $10 \mathrm{I}$-Units. Para o material RCO, embora o resultado médio esteja satisfatório, o desvio padrão se destaca negativamente em consequência da alta velocidade do material na saída do trem acabador, para cumprir com o alvo de temperatura de acabamento exigido juntamente com a espessura crítica do material. Para minimizar este efeito, o material é programado em posição do cone de laminação que permita ajuste preliminar da planicidade entre cadeiras para material de dimensão semelhante, para quando da laminação do material mais crítico, o ajuste ocorra de maneira mais eficiente. 
Planicidade Média vs Dimensional de Produto

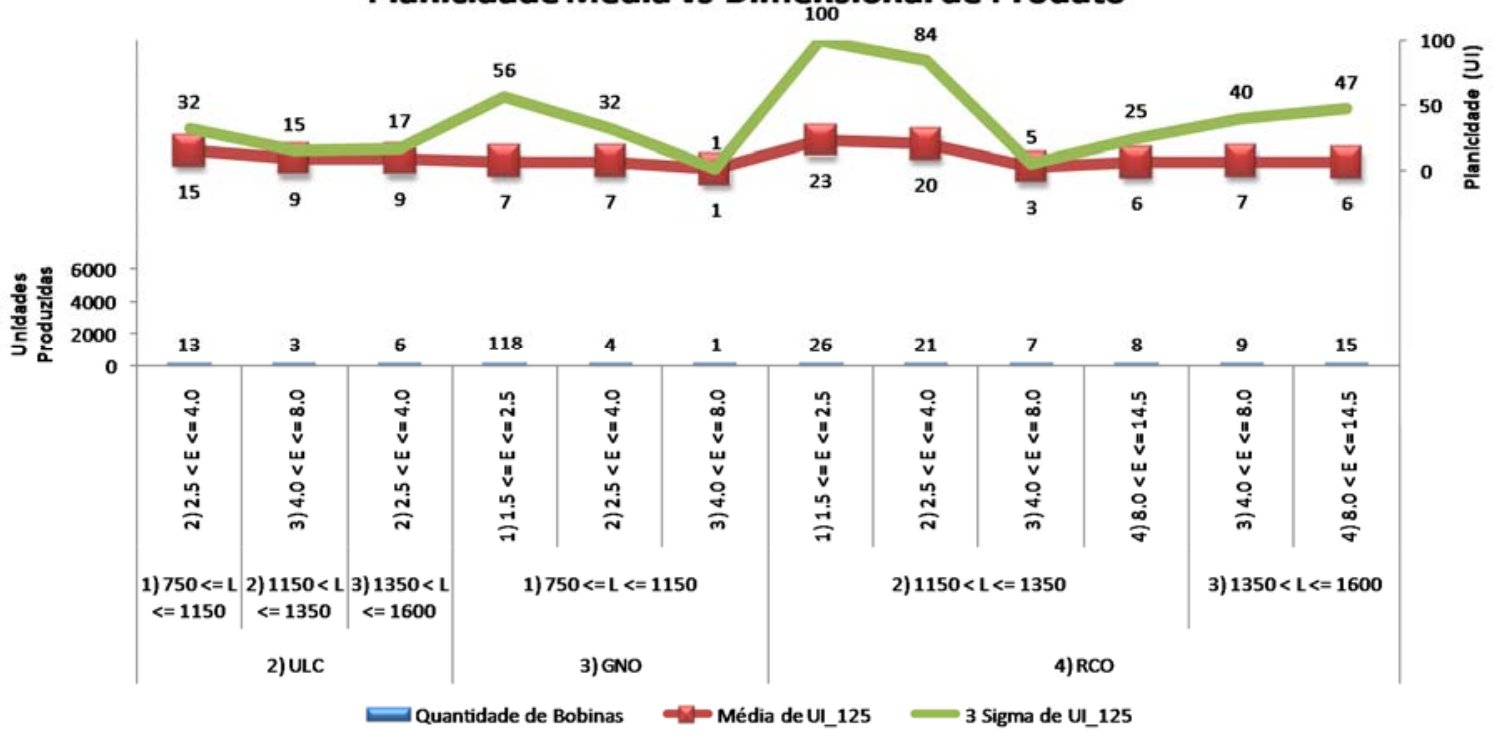

Figura 9. Resultado de planicidade da família ULC / GNO / RCO.

A família de material microligado tem participação considerável no mix de laminação, com aumento de produção ao longo do tempo e resultado de planicidade dentro de faixas esperadas. É o material com grande exigência de carga no laminador, principalmente material fino e largo, o que acarreta em maior valor de média de planicidade encontrada. Pela complexidade, as dimensões mais críticas do material microligado sofrem laminação de acabamento como rota, permitindo melhor planicidade ao produto acabado.

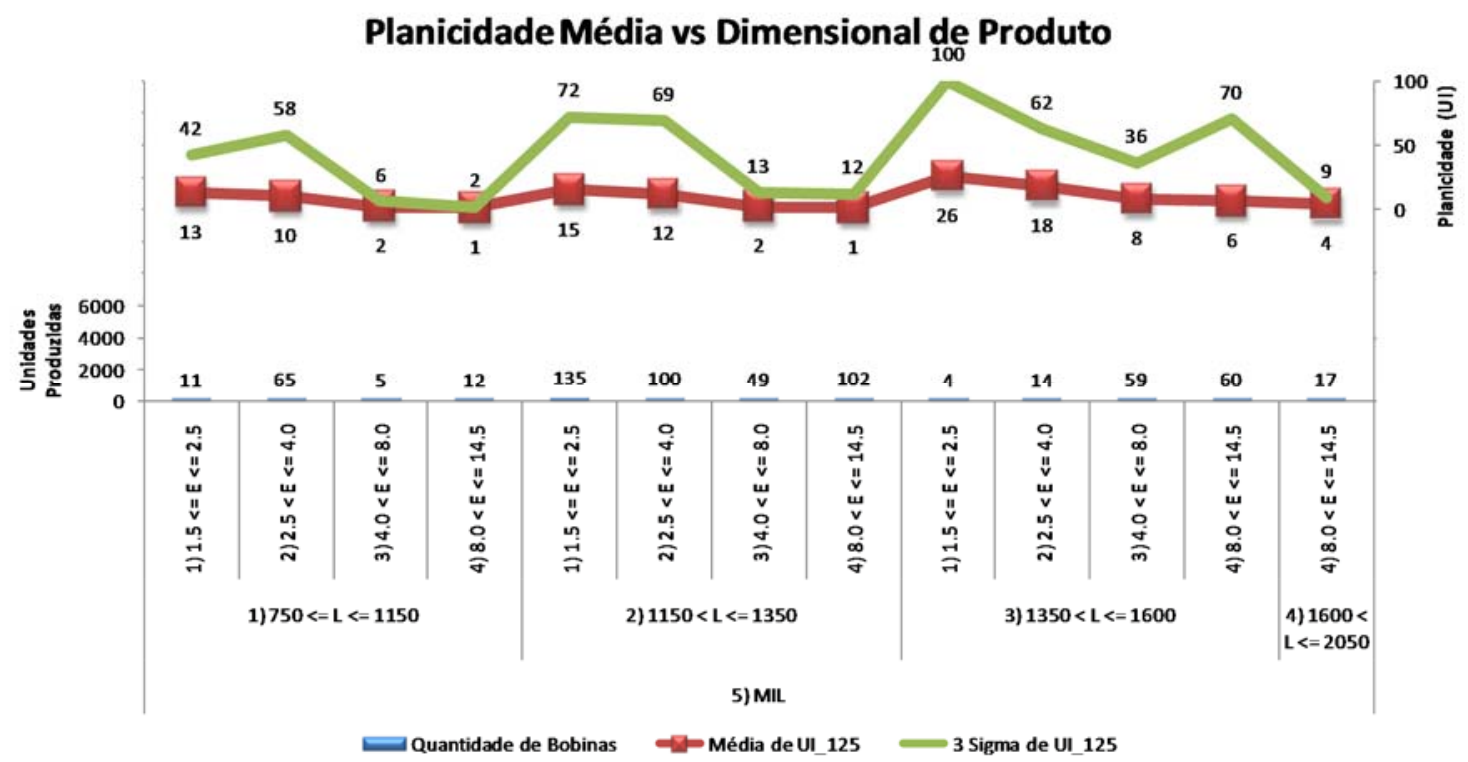

Figura 10. Resultado de planicidade da família MIL.

A família de materiais dual phase possui pequeno grupo amostral para análise, e conta com a peculiaridade de sofrer tratamento térmico brusco durante 0 resfriamento entre o trem acabador e bobinadeira. A planicidade encontrada na saída do trem acabador apresenta resultados médios abaixo dos 10 I-Units, com baixo desvio padrão. Para a família API, de aplicação em materiais grossos, o 
resultado também apresenta valores médios muito baixos, com o desvio padrão de maior magnitude conforme aumento de largura.

\section{Planicidade Média vs Dimensional de Produto}

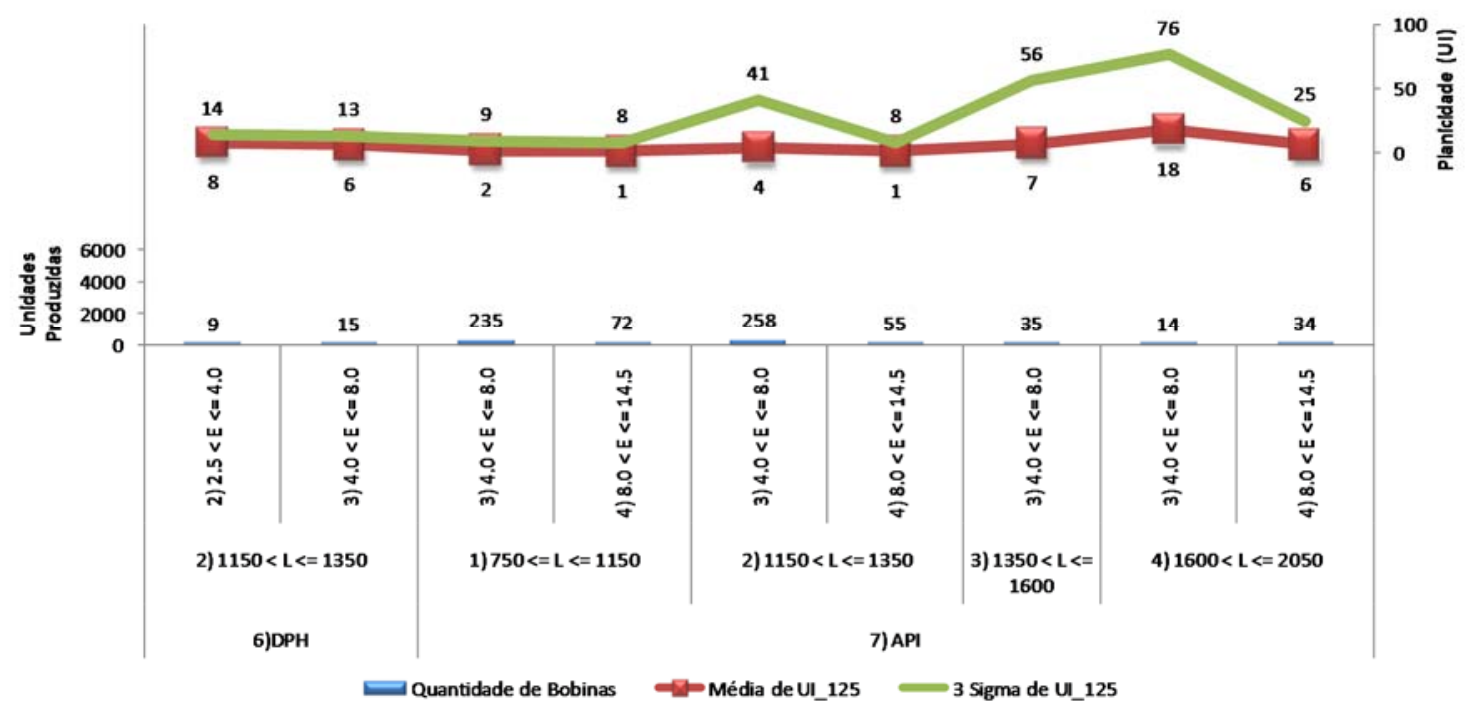

Figura 11. Resultado de planicidade da família DPH / API.

\section{CONCLUSÃO}

Neste trabalho foi apresentado o controle de perfil e planicidade das bobinas produzidas no novo laminador de tiras a quente da Usiminas de Cubatão, com suas ferramentas e métodos para atuação na busca da planicidade isenta de defeitos de ondulação. Este modelo permite à Usiminas atender as mais exigentes expectativas de mercado, com a possibilidade de medição, ajuste dinâmico e controle desta variável. Foi apresentada uma amostra dos resultados, com sucesso no quesito avaliado. $\mathrm{O}$ aprendizado citado no trabalho permite não só a melhoria contínua da forma dos materiais já contidos na colméia de produtos, como também o desenvolvimento progressivo de novas laminações em dimensões cada vez mais críticas, tornando o laminador e consequentemente o grupo Usiminas mais competitivo diante de cenário atual.

\section{Agradecimentos}

Supervisores de turno, técnicos operacionais e operadores da laminação a quente da Usiminas Cubatão pelo suporte e companheirismo dados durante a execução dos trabalhos.

\section{REFERÊNCIAS}

1 Yang Q, He A, Shao J. Asymmetric Shape Control Theory and Practice in Hot Strip Mills and Cold Strip Mills. National Engineerign Research Center of Flat Rolling Equipment. University of Science \& Technology Beijing, Beijing 100083, China.

2 Blazevic DT. Build Up (Ridges) - a 40 Years Odyssey. $15^{\text {th }}$ Rolling Conference. Instituto Argentino de Siderurgia 2005.

3 Pereira MM, Marconato EA, da Silva MRS, Vallin PSS. Novo Laminador de Tiras a Quente de Cubatão. $47^{\circ}$ Seminário de Laminação, Associação Brasileira de Metalurgia, Materiais e Mineração, Belo Horizonte, 2012. 